\title{
Dietary Cancer Chemopreventive Agents - Targeting Inflammation and Nrf2 Signaling Pathway
}

Author

Affiliation
Tin Oo Khor, Siwang Yu, Ah-Ng Kong

Center for Cancer Prevention Research and Department of Pharmaceutics, Ernest-Mario School of Pharmacy, Rutgers, the State University of New Jersey, Piscataway, NJ, USA
Key words

- inflammation

- isothiocyanates

- curcumin

- Nrf2

- cancer chemoprevention

received July 30,2008

revised August 18, 2008

accepted August 28, 2008

Bibliography

DOI $10.1055 / \mathrm{s}-0028-1088303$

Planta Med 2008; 74: 1540-

1547

(c) Georg Thieme Verlag KG

Stuttgart · New York

Published online October 20,

2008

ISSN 0032-0943

\section{Correspondence}

\section{Ah-Ng Tony Kong}

Department of Pharmaceutics

Ernest-Mario School of

Pharmacy

Rutgers, the State University of

New Jersey

160 Frelinghuysen Road

Piscataway

NJ 08854

USA

Tel.: +1-732-445-3831 x228

Fax: +1-732-445-3134

KongT@rci.rutgers.edu

\section{Abstract \\ $\nabla$}

Accumulating epidemiological and clinical evidence shows that chronic inflammation plays a critical role in neoplastic transformation and progression. Long-term users of selective cycloxygenase-2 (Cox-2) inhibitors (coxibs) and non-steroidal anti-inflammatory drugs (NSAIDs) have been reported to have a reduced risk of developing colorectal cancer. However, the adverse gastrointestinal and cardiovascular side effects associated with these drugs have limited their routine use for cancer chemoprevention. Basic leucine zipper (bZIP) protein Nrf2, a key transcription factor mediating the antioxidant response is an important modulator of tumor susceptibility

\section{Introduction}

$\nabla$

Chronic inflammation was identified as one of the predisposing factors for neoplastic transformation by Rudolph Virchow over a century ago. Today, his hypothesis is supported by accumulating epidemiological and clinical evidence. It is estimated that $15 \%$ of malignancies are associated with chronic inflammation as a result of persistent pathogen infections [1]. Studies from our laboratory, as well as the findings of others, demonstrated that nuclear factor-erythroid 2-related factor 2 (Nrf2) plays a crucial role in modulating susceptibility to carcinogenesis in mouse models [2], [3], [4], [5], [6], [7], [8]. This review will focus on the role of chronic inflammation and the Nrf2 signaling pathway in carcinogenesis and the feasibility of targeting inflammation and Nrf2 for cancer chemoprevention. Isothiocyanates and curcumin will be used as examples of natural phytochemicals that showed significant anti-inflammatory and cancer chemopreventive effects in rodent and human trials. in mouse models. Mice lacking Nrf2 are more susceptible to carcinogenesis induced by carcinogens. Moreover, induction of the Nrf2 signaling pathway is essential for many food phytochemicals to exert their cancer chemopreventive activity as demonstrated in many preclinical studies. It has been recently shown that the combination of coxibs or NSAIDs and natural phytochemicals can synergistically inhibit carcinogenesis in rodent models. This review will focus on the role of chronic inflammation and the Nrf2 signaling pathway in carcinogenesis and the feasibility of targeting these signaling pathways with dietary cancer chemopreventive agents and for cancer chemoprevention.

\section{Chronic Inflammation as a Risk Factor for Neoplastic Transformation \\ $\nabla$}

Acute inflammation is part of the innate immunity required to maintain integrity of the host when it is wounded by an infection, chemical or physical irritant [9]. Initiated by a cascade of cytokines and chemokines interactions, leukocytes and other phagocytic cells infiltrate the wounded tissues followed by the generation of oxidative stress [10]. Enhanced cell proliferation for tissue regeneration and other inflammatory responses subside after the assaulting agent is removed, marking completion of the healing process. However, neoplastic transformation may occur when the wounded tissues fail to heal or the healing process is dysregulated [11]. It is believed that persistent inflammatory cell recruitment, repeated generation of pro-inflammatory cytokines, reactive oxygen/nitrogen species, and continued proliferation of genomically unstable cells contribute to neoplastic transformation and ultimately result in tumor invasion and metastasis. 
One of the most obvious causal relationships between chronic inflammation and cancer is in colon carcinogenesis. Epidemiological studies have shown that individuals with long-standing inflammatory bowel diseases (IBD), such as ulcerative colitis and Crohn's disease have an increased lifetime risk of developing colorectal cancer [12], [13], [14]. While the infectious organism responsible for IBDs is yet to be identified, many pathogenic infections have been linked with cancers. It is estimated that $90 \%$ of ulcers and $60 \%$ of gastric adenocarcinomas are attributed to $H$. pylori infection [15]. Approximately $85 \%$ of patients infected by $H$. pylori remain asymptomatic but in the remaining $15 \%$ infection is associated with gastritis, peptic ulcers and gastric adenocarcinoma [16], [17]. It has been shown that in patients with vacA cytotoxin-expressing $H$. pylori, infection is associated with a higher degree of inflammation and they are significantly more likely to develop peptic ulcers or gastric cancer [18]. In fact, antibiotic therapy against $H$. pylori has been found to effectively prevent gastritis, peptic ulcers and ultimately gastric cancer [19], [20], [21]. Accumulating epidemiological evidence links chronic HBV and HCV infection with hepatocellular carcinoma (HCC) in humans [22], [23], [24], [25], [26]. It is believed that liver cancer is the consequence of a chronic process of active hepatitis that produces a continuous stimulus of hepatic regeneration and cirrhosis [27]. Likewise, increased risk for bladder cancer is associated with schistosomiasis [28], [29], [30] and opisthorchiasis increases the risk of cholangiocarcinoma by more than five-fold [31]. In addition to infections, environmental or chemical toxicants and physical irritants may also trigger chronic inflammation leading to increase tumor risks ( $\bullet$ Table 1 ).

\section{Nrf2 as an Important Modulator of Susceptibility to Carcinogenesis - Preclinical evidence \\ $\nabla$}

Nuclear factor-erythroid 2-related factor 2 ( Nrf2) is a transcriptional factor that plays a crucial role in cytoprotection against inflammation, as well as oxidative and electrophilic stresses. Upon oxidative or electrophilic insults, Nrf2 will translocate into the nucleus where it binds with antioxidant response elements, and transactivates phase II detoxifying and antioxidant genes. Among the antioxidant genes that are regulated by Nrf2 are $\mathrm{NAD}(\mathrm{P}) \mathrm{H}$ :quinone oxidoreductase (NQO1), heme oxygenase-1 (HO-1), thioredoxin reductase 1 , glutamate-cysteine ligase modifier subunit and glutamate-cysteine ligase catalytic subunit [32]. Findings from our laboratory and others have demonstrated that Nrf2 is an important modulator of susceptibility to carcinogen-induced carcinogenesis ( $\bullet$ Table 2 ). Using an azoxymethane-dextran sodium sulfate (AOM/DSS) colon carcinogenesis model, we demonstrated that tumor incidence, multiplicity, size, and stage of progression are increased in Nrf2 deficient mice [33]. Similarly, Osburn et al. in 2007 reported that Nrf2 ablation resulted in increased colonic inflammatory injury and formation of aberrant crypt foci upon DSS treatment [8]. We have also reported that Nrf2-deficient mice are more susceptible to 7,12-dimethylbenz[a]anthracene (DMBA) and 12-O-tetradecanoylphorbol 13-acetate (TPA)-induced skin tumorigenesis [4]. In addition, accelerated DNA adduct formation and severe epithelial hyperplasia induced by diesel exhaust exposure, increased gastric neoplasia induced by benzopyrene. Increased incidences of $\mathrm{N}$-nitrosobutyl(4-hydroxybutyl)amine (BBN)-induced urinary bladder carcinoma and hepatocarcinogenesis induced by 2-amino-3-methylimidazo[4,5-f]quinoline were also reported in Nrf2-deficient mice compared to their wild-type counterparts [2], [3], [6], [7]. Taken together, it is obvious that $\mathrm{Nrf} 2$ functions as a suppressor of tumorigenesis, at least in preclinical animal models.

\section{NF- $k B$ Signaling and the Inflammatory Pathways} $\nabla$

A key player in inflammatory processes is the transcription factor NF- $\kappa B$ (nuclear factor-kappa-B) [34], which consists of a number of closely related protein dimers that bind a common sequence motif [35]. Consisting of homo- and heterodimeric complexes formed from the Rel family of proteins, Rel/NF- $\kappa \mathrm{B}$ nuclear transcription factors have been found to play important

Table 1 Chronic inflammation-associated non-malignant diseases and malignancy

\begin{tabular}{|c|c|c|}
\hline Etiological agents & Non-malignant disease & Malignancy \\
\hline \multicolumn{3}{|l|}{ Environmental/Chemical irritants } \\
\hline Asbestos fibres, silica dusts & Asbestosis, silicosis (Grinder's disease) & Mesothelioma, lung carcinoma \\
\hline Cigarettes smoking & Bronchitis & Lung carcinoma \\
\hline Alcohol & Pancreatitis, liver cirrhosis & $\begin{array}{l}\text { Pancreatic carcinoma, hepatocellular } \\
\text { carcinoma }\end{array}$ \\
\hline Ultraviolet light & Skin inflammation & Melanoma \\
\hline Gastric acids & Reflux esophagitis, Barrett's esophagus & Esophageal carcinoma \\
\hline \multicolumn{3}{|l|}{ Pathogen infections } \\
\hline Human papilloma virus 16 and 18 (HPV) & Genital warts/condyloma & Cervical cancer \\
\hline Epstein-Barr virus (EBV) & Infectious mononucleosis & $\begin{array}{l}\text { Nasopharyngeal carcinoma, Burkitt's } \\
\text { lymphoma, Hodgkin's lymphoma }\end{array}$ \\
\hline Hepatitis B and C virus (HBV, HCV) & Hepatitis, cirrhosis & Hepatocellular carcinoma \\
\hline $\begin{array}{l}\text { Human herpes } 8 \text { (HH8), human immuno- } \\
\text { deficiency virus (HIV) }\end{array}$ & AIDS & $\begin{array}{l}\text { Kaposi's sarcoma, squamous cell carcinoma, } \\
\text { non-Hodgkin's lymphoma }\end{array}$ \\
\hline Liver flukes (Opisthorchis viverrini) & Opisthorchis, cholangitis & Cholangiosarcoma, colon carcinoma \\
\hline Helicobacter pylori & Gastritis, peptic ulcers & Gastric carcinoma \\
\hline Schistosoma haematobium & Schistosomiasis & Bladder carcinoma \\
\hline \multicolumn{3}{|l|}{ Unidentified factor } \\
\hline & $\begin{array}{l}\text { Inflammatory bowel diseases (IBDs), } \\
\text { Crohn's disease, chronic ulcerative colitis }\end{array}$ & Colorectal carcinoma \\
\hline
\end{tabular}


Table $2 \mathrm{Nrf2}$ as important modulator of tumor susceptibility in mouse models

Carcinogen
Azoxymethane/dextran sulfate sodium (AOM/DSS)
Diesel exhaust particles
Benzo[a]pyrene (B[a]P)
7,12-Dimethylbenz[a]anthracene/12-O-tetradecanoylphorbol
13-acetate (DMBA/TPA)
N-Nitrosobutyl-(4-hydroxybutyl)amine (BBN)
2-Amino-3-methylimidazo[4,5-f]quinolone
Modified from ref. [81].
* As observed in Nrf2-deficient mice in comparison to their wild-type counterparts.

roles in cell proliferation, anti-apoptosis, and cancer development. The Rel protein family consists of five proteins, named cRel, Rel A (p65), Rel B, NF-kB1 (p50/p105), and NF- $к B 2$ (p52/ $\mathrm{p} 100)$. NF- $\kappa \mathrm{B}$ is activated by a wide variety of stimuli such as tumor necrosis factor (TNF)-alpha, interleukin-1 (IL-1), LPS, UV light, and oxidative stress. In most cell types, NF- $\mathrm{kB}$ is present in the cytosol in an inactive form and is associated with its inhibitor proteins, called inhibitor of NF- $\mathrm{KB}(\mathrm{I}-\mathrm{kBS})$. Of the many functional domains in NF- $\kappa \mathrm{B}$ proteins - the Rel homology domain (RHD), DNA binding domains, the dimerization domain, and the nuclear localization signal (NLS) - I- $\kappa$ Bs bind to the RHD. Activation of NF- $\kappa$ B by extracellular stimuli leads to rapid phosphorylation, ubiquitination, and proteolytic degradation of $\mathrm{I}-\kappa \mathrm{B}$, thereby exposing the nuclear localization signals on NF- $\kappa \mathrm{B}$ and resulting in the nuclear translocation of the NF- $\kappa \mathrm{B}$ complex and phosphorylation of $\mathrm{p} 65$. The binding of NF- $\mathrm{kB}$ to a specific sequence in the promoter region of a gene triggers the transcriptional activation of NF- $\mathrm{kB}$-regulated genes, including cyclin D1, vascular endothelial growth factor (VEGF), Bcl-XL, COX-2, and MMP-9, which are involved in a variety of cellular events, including tumor cell proliferation, angiogenesis and metastasis [36]. Hence, $\mathrm{NF}-\mathrm{KB}$ and the signaling pathways that mediate its activation have become attractive targets for development of new chemopreventive and chemotherapeutic approaches [34].

\section{Cross-Talk between Inflammation and Nrf2 Signaling Pathway \\ $\nabla$}

There is a growing body of evidence that the Nrf2 signaling pathway is closely involved with the regulation of inflammation. We have recently shown that Nrf2-deficient mice have increased susceptibility to DSS-induced colitis. In comparison with wildtype mice, the colonic colitis observed in Nrf2 KO mice appeared to be more severe as demonstrated by loss of colonic crypts, massive infiltration of inflammatory cells and anal bleeding. In addition, immunocytochemical staining of nitrotyrosine, a biomarker of inflammation, was more intense in Nrf2 KO mice. These observations in $\mathrm{KO}$ mice were associated with a lower induction of phase II detoxifying genes/enzymes including HO-1, NAD(P)H-quinone reductase-1 (NQO1), UDP-glucurosyltransferase 1 A1 (UGT1A1), and glutathione $S$-transferase Mu-1 (GSTM1). Concomitantly, more intense induction of pro-inflammatory biomarkers, such as interleukin (IL)-1 $\beta$, IL- 6 and TNF $\alpha$, as well as pro-inflammatory mediators like inducible nitric oxide synthetase (iNOS) and cyclooxygenase 2 (COX2), was observed in Nrf2 KO mice [37]. It has been shown that Nrf2 protects against

\section{Outcomes*}

Increased incidence, tumor multiplicity, and invasiveness of colon adenocarcinoma

Increased DNA adduct formation and epithelial hyperplasia Increased multiplicity of gastric carcinoma

Increased multiplicity of skin papillomas

Increased incidence and invasiveness of bladder carcinoma Increased incidence and multiplicity of liver tumors.

chemical-induced pulmonary injury and inflammation [38], [39], whereas genetic ablation of Nrf2 enhances the susceptibility to cigarette smoke-induced emphysema and to severe airway inflammation and asthma in mice [40], [41]. In addition, Nrf2 was found to be a crucial regulator of the innate immune response and survival during experimental sepsis [42]. It is postulated that attenuation of inflammation through induction of anti-oxidative enzymes and suppression of pro-inflammatory mediators in an Nrf2-dependent manner, as demonstrated in these acute inflammation animal models, results in decreased sensitivity of wild-type mice towards inflammatory oxidative damage. These studies show that the Nrf2 signaling pathway is essential for protection of the host against inflammation and inflammatory damage.

Despite all the findings in preclinical models suggesting that there is a possible cross-talk between Nrf2 and inflammation, the underlying mechanisms are still elusive. Liu et al. have recently provided an important insight, elucidating how pro-inflammatory signaling can negatively regulate the Nrf2/ARE signaling pathway [43]. They found that NF- $\kappa \mathrm{B} / \mathrm{p} 65$ could antagonize this pathway through deprivation of the coactivator, CREB binding protein (CBP) from Nrf2. They also hypothesized that disruption of Nrf2-CBP interaction may restore the ability of CBP to recruit the corepressor, histone deacetylases (HDACs) to ARE resulting in ARE repression [43]. Since in vivo data indicated that ablation of Nrf2 resulted in increased expression of pro-inflammatory mediators like IL- $1 \beta$, IL-6 and Cox-2, which are modulated by NF- $\kappa \mathrm{B}$, it will be interesting to know if overexpression of Nrf2 can reverse the suppression effect of p65 leading to suppression of the pro-inflammatory NF- $\kappa$ B signaling pathway. A previous study showed that Nrf1 and Nrf2 can differentially modulate the expression of NF- $\kappa \mathrm{B}$ and activator protein-1 (AP1) family members [44]. The question whether modulation of these pro-inflammatory mediators by Nrf2 is a direct transcriptional regulation or indirect through its transactivated target genes such as HO-1 and NQO-1 requires further investigation.

\section{Cancer Chemoprevention by Targeting Inflammation and Nrf2 Signaling Pathway $\nabla$}

Some of the best evidence for a causal relationship between inflammation and neoplastic transformation and progression comes from a study of cancer risk among long-term users of aspirin and non-steroidal anti-inflammatory drugs (NSAIDs). Epidemiological studies conducted on different populations with 
more than 13,000 cases, indicate that regular aspirin use is associated with a reduction in the risk of colorectal cancer. The pooled relative risk (RR) estimation was 0.59 (95\% CI: 0.54 0.64 ) from 11 case-control studies, 0.85 (95\% CI: 0.78 - 0.92) from seven cohort ones, and $0.71(95 \% \mathrm{CI}: 0.67-0.75)$ from all studies combined [45]. In addition, epidemiological studies also indicate that aspirin has a favorable effect on cancers of the esophagus ( $R R=0.72,95 \% \mathrm{CI}: 0.62-0.84)$, stomach $(\mathrm{RR}=0.84$, $95 \% \mathrm{CI}: 0.76-0.93)$, breast $(\mathrm{RR}=0.91,95 \% \mathrm{CI}: 0.88-0.95)$, ovary $(\mathrm{RR}=0.89,95 \% \mathrm{CI}: 0.78-1.02)$ and lung $(\mathrm{RR}=0.94,95 \% \mathrm{CI}: 0.89$ -1.00 ) [45]. From the perspective of all these promising findings, the development of effective chemoprevention with these drugs appears to be a real possibility. However, several obstacles and challenges remain to be overcome. While the optimum doses and the duration of treatment needed to achieve an effective chemopreventive effect remain unclear, long-term consumption of these drugs is associated with adverse side effects. Therefore, cancer chemoprevention using coxibs and NSAIDs may only be suitable for patients with higher cancer risk.

\section{Natural Phytochemicals as Promising Anti- Inflammatory and Anti-Neoplastic Agents $\nabla$}

Naturally occurring compounds with potent anti-inflammatory properties have been noted as a plausible approach for clinical cancer prevention trials. In fact, dietary vegetables and fruits have been regarded as rich sources of chemopreventive agents. Food phytochemicals such as curcumin, EGCG, resveratrol, genistein and isothiocyanates, with strong anti-inflammatory activity, have been shown to inhibit carcinogenesis in preclinical animal models. Epidemiological studies have clearly documented that the frequent consumption of a diet high in fruits and vegetables has been linked to a lower risk of many types of cancers including prostate, colon, oral cavity, stomach, lung and esophagus [46], [47]. For example, several case-control and large prospective studies focusing on dietary assessment suggest that the intake of isothiocyanates, tomatoes and tomato-based food products may be associated with a lower risk of prostate cancer [48], [49], [50], [51], [52]. Furthermore, several studies reported that broccoli consumption could be linked to a lowered risk of colon cancer and that watercress consumption can inhibit oxidative metabolism of lung carcinogen NNK in humans, as reported in rodents [53]. In addition, intakes of yellow-orange and cruciferous vegetables were also inversely related to prostate cancer, especially for advanced cases, with findings that were generally consistent across ethnic groups and these results suggest that legumes (not limited to soy products) and cruciferous vegetables may protect against prostate cancer. Other nutritional epidemiological studies also provide support for the hypothesis that high intakes of Brassica vegetables reduce prostate cancer risk [54], [55].

\section{Isothiocyanates}

Cruciferous vegetables, such as broccoli, Brussels sprouts, watercress, cabbage, kale, cauliflower, kohlrabi and turnip, are rich sources of sulfur-containing compounds called glucosinolates. Strong anticarcinogenic activities of cruciferous vegetables have been attributed to the high abundance of isothiocyanates (ITCs), hydrolysis products of glucosinolates. Isothiocyanates such as sulforaphane, phenethyl isothiocyanate (PEITC), benzyl isothiocyanate (BITC) and allyl isothiocyanate (AITC) have been repor- ted to inhibit carcinogen-induced tumorigenesis in a variety of preclinical rodent models [56], [57]. With over 115 naturally occurring glucosinolates identified to date, various cancer chemopreventive mechanisms have been proposed for the ITCs. These include induction of antioxidant and phase $\mathrm{I} / \mathrm{II}$ detoxification genes through activation of Nrf2 (NF-E2 related factor 2) and AhR (arylhydrocarbon receptor), inhibition of pro-inflammatory signaling pathways by suppression of NF- $\kappa \mathrm{B}$ (nuclear factor $-\kappa \mathrm{B}$ ), inhibition of histone deacetylase, as well as induction of cell cycle arrest and apoptosis. An excellent review on the cancer chemopreventive actions of phytochemicals derived from glucosinolates has been recently written by Hayes et al. [58]. As mentioned earlier, blocking chronic inflammation is an important step in the prevention of cancers. Isothiocyanates have been found to exhibit anti-inflammatory activity probably through inhibition of the NF- $\kappa B$ signaling pathway. Heiss et al. reported that the anti-inflammatory effect of sulforaphane is elicited through the inhibition of NF- $\kappa \mathrm{B}$ and provided novel evidence that anti-inflammatory mechanisms may contribute to sulforaphane-mediated cancer chemoprevention [59]. In vitro studies from our laboratory suggest that sulforaphane and PEITC inhibit the transcriptional activity of NF- $\kappa \mathrm{B}$ through the inhibition of phosphorylation of I $\kappa \mathrm{B}$, the inhibitor of NF- $\kappa \mathrm{B}$ [60]. Using HT-29 human colon cancer cell lines stably transfected with the NF- $\kappa \mathrm{B}-$ luciferase-reporter construct, we found that ITCs, including PEITC, AITC and sulforaphane substantially inhibited lipopolysacharride (LPS)-induced NF- $\kappa$ B luciferase activity in a dose-dependent manner [61]. We have recently reported that sulforaphane and dibenzoylmethane, given alone or in combination, inhibit familial adenomatous polyposis in APCmin/+ mice [62]. Both sulforaphane and DBM treatments resulted in decreased levels of pro-inflammatory prostaglandin E2 or leukotriene B4 in intestinal polyps or apparently normal mucosa. In addition, winter cress (Barbarea verna) seed preparations rich in pheneth$\mathrm{yl}$ isothiocyanate (PEITC) showed strong in vivo anti-inflammatory activity by significantly reducing the size of carrageenan-induced rat paw edema. The seed preparations were found to be able to reduce the mRNA levels of inflammation-related genes such as COX-2, iNOS and the pro-inflammatory cytokine interleukin in LPS-stimulated mouse macrophage cell line RAW 264.7 [63]. These studies indicate that ITCs are potent anti-inflammatory agents and the inhibition of inflammation by ITCs may contribute to their overall cancer chemopreventive effects. Previous studies from our laboratory as well as others have demonstrated that the induction of anti-oxidant/phase II detoxification through activation of Nrf2 signaling is a crucial mechanism for many phytochemicals to block cancers. We have recently reported that inhibition of 7,12-dimethylbenz[a]anthracene-induced skin tumorigenesis in $\mathrm{C} 57 \mathrm{BL} / 6$ mice by sulforaphane is mediated by Nrf2 [4]. Similarly, inhibition of benzo[ $a$ ]pyrene-induced forestomach tumor by oltipraz and sulforaphane and inhibition of urinary bladder carcinogenesis by oltipraz were all found to be Nrf2-dependent [3], [6], [64], [65]. Recently, Kensler et al. initiated a human clinical trial to investigate the effect of a glucosinolate-rich broccoli sprout hot water extract on the genotoxicity of aflatoxin and found a significant inverse relationship between sulforaphane elimination and urinary aflatoxin-DNA adduct excretion in individual participants [66]. This finding demonstrated that, in humans, sulforaphane may prevent the carcinogenic potential of aflatoxin exposure by modulating its metabolism, potentially through an Nrf2-mediated mechanism. 


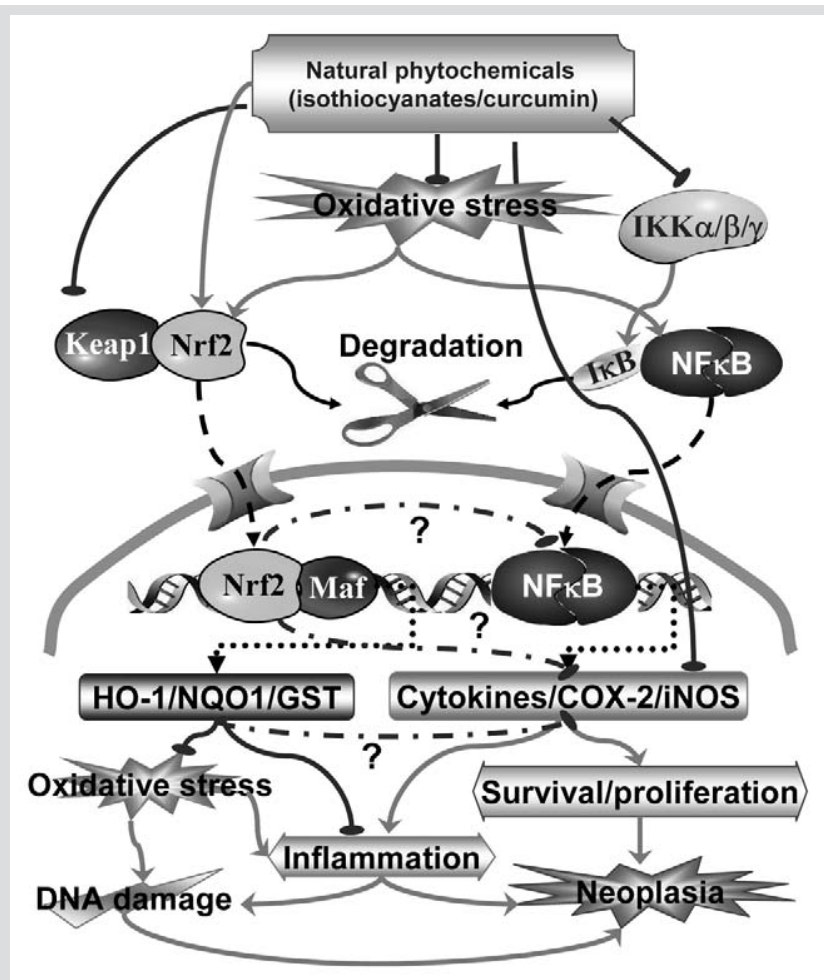

Fig. 1 Overall schematic of possible cross-talk between Nrf2 and inflammatory signaling pathways in cancer promotion and progression. Excessive oxidative stress coupled with prolonged inflammatory response (probably through activation of NF- $\kappa B$ signaling pathways) leads to cancer promotion and progression. Natural phytochemicals such as CUR and isothiocyanates activate Nrf2-mediated antioxidant enzymes (leading to decreased oxidative stress/inflammation and cell growth) and inhibit the NF$\kappa \mathrm{B}$-mediated inflammatory pathway (leading to decreased inflammation and cell growth) resulting in protection against inflammation and cancer. Red arrow: activation; Blue line: inhibition; Dotted blue line: presumed inhibition; Black dotted arrow: transcriptional activation

\section{Curcumin}

Curcumin (CUR, a beta-diketone), a constituent of turmeric curry powder, possesses potent anti-inflammatory activity and prevents cancer in many animal models [67], [68], [69], [70], [71]. CUR is a potent inhibitor of TPA-induced ornithine decarboxylase activity and inflammation in mouse skin [69]. CUR is also a potent inhibitor of arachidonic acid-induced inflammation in vivo in mouse skin, and inhibits epidermal lipoxygenase and cyclooxygenase activity in vitro [69]. CUR inhibits COX2 induction by the tumor promoters, and TNF $\alpha$. The induction of COX2 by inflammatory cytokines or hypoxia-induced oxidative stress can be mediated by NF- $\kappa$ B. Since CUR inhibits NF- $\kappa$ B activation, Plummer et al. examined whether its chemopreventive activity is related to modulation of the signaling pathway that regulates the stability of the NF-kappaB-sequestering protein, I $\mathrm{B}$ [72]. Recently components of this pathway, NF- $\kappa \mathrm{B}$-inducing kinase and $\mathrm{I} \kappa \mathrm{B}$ kinases IKKalpha and beta, which phosphorylate $\mathrm{I} \kappa \mathrm{B}$ to release NF- $\kappa B$, have been characterized. CUR prevents phosphorylation of $I \kappa B$ by inhibiting the activity of the IKKs. We have found that CUR potently inhibited phosphorylation of EGFR, PI3K, AKT, IKK-alpha and NF- $\kappa$ B activities in human prostate PC-3 cells [73], inhibition of NF- $\kappa$ B activities in human colon HT-29 cells [61] and that inhibition of Akt and NF- $\kappa \mathrm{B}$ signaling pathways could contribute to the inhibition of cell proliferation and induction of apoptosis in the PC-3 prostate tumor xenografts in nude mice. Dietary administration of $2 \%$ CUR also caused a marked increase in apoptosis, and a significant decrease in angiogenesis in nude mice treated with LNCap prostate cancer cells [74]. Similarly, dietary administration of $2 \%$ CUR effectively inhibited azoxymethane (AOM)-induced colon tumors in male F344 rats and prevented tumors in C57BL/6J-Apc Min/+ mice. CUR was also reported to inhibit AOM-induced rat colon carcinogenesis by suppression of prostaglandin (PG) and thromboxane (Tx) formation [75].

Similar to isothiocyanates, CUR is a strong activator of Nrf2mediated transcription of ARE-luciferase reporter gene, as well

Table 3 Synergistic inhibitory effect of coxibs and NSAIDs and food phytochemicals combination against carcinogenesis in rodent models

\begin{tabular}{|c|c|c|c|}
\hline Drugs/compounds (Dose) & Model & Outcome & Ref. \\
\hline $\begin{array}{l}\text { Curcumin }(0.6 \%) \text {, Celecoxib } \\
(0.16 \%)\end{array}$ & $\begin{array}{l}\text { 2,3-Dimethylhydrazine (DMH)- } \\
\text { induced colon cancer in rat }\end{array}$ & $\begin{array}{l}\downarrow 39 \%, \downarrow 26.5 \% \text { and } \downarrow 62 \% \text { for curcumin, celecoxib, and } \\
\text { combination, respectively. }\end{array}$ & {$[82]$} \\
\hline $\begin{array}{l}\text { Green tea polyphenol (GTP) } \\
(0.1 \%) \text {, celecoxib }(10 \mathrm{mg} / \mathrm{kg} \text { i.p. } \\
5 \text { days/week) }\end{array}$ & $\begin{array}{l}\text { CWR22Rv1 xenografts in nude } \\
\text { mice }\end{array}$ & $\begin{array}{l}\downarrow 42 \%, \downarrow 57 \% \text { and } \downarrow 81 \% \text { for GTP, celecoxib alone and } \\
\text { combination, respectively }\end{array}$ & {$[83]$} \\
\hline $\begin{array}{l}\text { alpha-Tocopherol ether-linked } \\
\text { acetic acid analogue ( } \alpha \text {-TEA) } \\
\text { ( } 72 \mathrm{mg} / \text { day aerosol inhalation), } \\
\text { celecoxib ( } 500 \mathrm{ppm})\end{array}$ & $\begin{array}{l}\text { Ultraviolet-induced skin cancers } \\
\text { in mice }\end{array}$ & $\begin{array}{l}\downarrow \text { tumor numbers in all treatment group but continuous } \\
\text { combination treatment resulted in the lowest total number of } \\
\text { tumor }\end{array}$ & {$[84]$} \\
\hline $\begin{array}{l}\text { ( } 72 \mathrm{mg} / \text { day aerosol inhalation), } \\
\text { celecoxib ( } 500 \mathrm{mg} / \mathrm{kg} \text { and } \\
1250 \mathrm{mg} / \mathrm{kg} \text { diet) }\end{array}$ & $\begin{array}{l}\text { MDA-MB-435-FL-GFP human } \\
\text { cancer xenografts in nude mice }\end{array}$ & $\begin{array}{l}\downarrow \text { mean tumor volume in all treatment group; inhibitory effect } \\
\text { significantly stronger in combination of } \alpha \text {-TEA + celecoxib } \\
(1250) \text { group than single compound } / \text { drug }\end{array}$ & {$[85]$} \\
\hline $\begin{array}{l}\text { Fructo-oligosaccharide ( } 6 \%) \\
\text { celecoxib } 1500 \mathrm{ppm}\end{array}$ & $\begin{array}{l}\text { AOM-induced aberrant crypt foci } \\
(A C F) \text { in rat }\end{array}$ & $\downarrow 61 \%$ in combination; no effect with celecoxib alone & [86] \\
\hline $\begin{array}{l}\text { Anthocyanin-rich tart cherry } \\
\text { extract ( } 375,750,1500, \\
3000 \mathrm{mg} / \mathrm{kg} \text { diet), sulindac } \\
\text { (100 mg/kg diet) }\end{array}$ & $\mathrm{APCmin} /+$ mice & $\begin{array}{l}\text { Anthocyanin-rich extract + sulindac had fewer and smaller total } \\
\text { tumor burden compared with sulindac alone }\end{array}$ & [87] \\
\hline $\begin{array}{l}\text { EGCG }(0.01 \%) \text {, sulindac } 10 \mathrm{mg} / \\
\mathrm{kg} \text { bw, p. o., } 3 \text { times/week }\end{array}$ & AOM-induced colon cancer in rat & $\begin{array}{l}\downarrow 54 \%, \downarrow 58 \% \text { and } \downarrow 78 \% \text { for EGCG, sulindac alone and } \\
\text { combination, respectively. }\end{array}$ & {$[88]$} \\
\hline $\begin{array}{l}\text { Green tea extract }(0.1 \%) \text {, } \\
\text { sulindac }(0.03 \%)\end{array}$ & $\mathrm{APCmin} /+$ & $\begin{array}{l}\downarrow 27 \%, \downarrow 32 \% \text { and } \downarrow 55.5 \% \text { for Green tea extract, sulindac alone } \\
\text { and combination, respectively. }\end{array}$ & {$[89]$} \\
\hline
\end{tabular}


as an inducer of endogenous Nrf2 protein and one of the Nrf2mediated detoxifying/antioxidant enzyme HO-1 in human cells [76]. Using Affymetrix microarray analysis on the gene expression profiles induced by CUR in $\mathrm{Nrf} 2(+/+)$, but not in $\mathrm{Nrf2}(-/-)$, our results indicated that, in addition to the classical Nrf2-mediated detoxifying and antioxidant cellular defense genes, other genes including transporters, kinases/phophatases, those involved in ubiquitination and proteolysis, electron transport, apoptosis and cell cycle control, cell adhesion and transcription factors also require $\mathrm{Nrf} 2$ for their induction by dietary cancer chemopreventive compounds including CUR [76]. All these properties, together with a long history of consumption without adverse health effects, make CUR an important candidate for consideration in human cancer prevention.

\section{Conclusion}

Given that chronic inflammation has been linked with almost $20 \%$ of all human malignancies [77], Nrf2 signaling is important in the defense of acute inflammation, both inflammation and Nrf2 seem to be plausible targets for cancer chemoprevention. - Fig. 1 summarizes the involvement and the possible crosstalk between Nrf2 and inflammatory signaling pathways. Concomitant induction of the Nrf2 signaling pathway and inhibition of inflammation is thought to be a crucial mechanism by which these phytochemicals exhibit their cancer chemopreventive effect. Combinations of sub-optimal doses of coxibs and NSAIDs such as celexocib and sulindac with relatively non-toxic natural phytochemicals such as CUR, isothiocyanates and EGCG have been proven to be able to synergistically inhibit carcinogenesis in rodent models ( Table 3 ). In addition to ongoing trials involving single phytochemicals with multiple activities, these combinational approaches certainly warrant further consideration in clinical human trials.

\section{Acknowledgements}

\section{$\nabla$}

We thank all the members of Ah Ng Tony Kong's laboratory for their helpful discussions. This study was supported in part by Institutional Funds and by R01-CA094828, R01-CA073674 and R01-CA118947 to Dr Ah-Ng Tony Kong from the National Institutes of Health (NIH).

\section{References}

1 Kuper H, Adami HO, Trichopoulos D. Infections as a major preventable cause of human cancer. J Intern Med 2000; 248: 171 - 83

2 Aoki Y, Sato H, Nishimura N, Takahashi S, Itoh K, Yamamoto M. Accelerated DNA adduct formation in the lung of the Nrf2 knockout mouse exposed to diesel exhaust. Toxicol Appl Pharmacol 2001; 173: 154-60

3 Ramos-Gomez M, Kwak MK, Dolan PM, Itoh K, Yamamoto M, Talalay P et al. Sensitivity to carcinogenesis is increased and chemoprotective efficacy of enzyme inducers is lost in nrf2 transcription factor-deficient mice. Proc Natl Acad Sci U S A 2001; 98: 3410-5

4 Xu C, Huang MT, Shen G, Yuan X, Lin W, Khor TO et al. Inhibition of 7,12dimethylbenz[a]anthracene-induced skin tumorigenesis in C57BL/ 6 mice by sulforaphane is mediated by nuclear factor E2-related factor 2. Cancer Res 2006; 66: 8293-6

5 auf dem Keller U, Huber M, Beyer TA, Kumin A, Siemes C, Braun S et al. Nrf transcription factors in keratinocytes are essential for skin tumor prevention but not for wound healing. Mol Cell Biol 2006; 26: 3773-84

6 Iida K, Itoh K, Kumagai Y, Oyasu R, Hattori K, Kawai K et al. Nrf2 is essential for the chemopreventive efficacy of oltipraz against urinary bladder carcinogenesis. Cancer Res 2004; 64: 6424-31
7 Kitamura Y, Umemura T, Kanki K, Kodama Y, Kitamoto S, Saito K et al. Increased susceptibility to hepatocarcinogenicity of Nrf2-deficient mice exposed to 2-amino-3-methylimidazo[4,5-f]quinoline. Cancer Sci 2007; 98: 19-24

8 Osburn WO, Karim B, Dolan PM, Liu G, Yamamoto M, Huso DL et al. Increased colonic inflammatory injury and formation of aberrant crypt foci in Nrf2-deficient mice upon dextran sulfate treatment. Int J Cancer 2007; 121: $1883-91$

9 Philip M, Rowley DA, Schreiber H. Inflammation as a tumor promoter in cancer induction. Semin Cancer Biol 2004; 14: 433-9

10 Maeda $H$, Akaike $T$. Nitric oxide and oxygen radicals in infection, inflammation, and cancer. Biochemistry (Mosc) 1998; 63: 854-65

11 Dvorak HF. Tumors: wounds that do not heal. Similarities between tumor stroma generation and wound healing. N Engl J Med 1986; 315: $1650-9$

12 Itzkowitz SH, Yio X. Inflammation and cancer IV. Colorectal cancer in inflammatory bowel disease: the role of inflammation. Am J Physiol Gastrointest Liver Physiol 2004; 287: G7 - 17

13 Brostrom O, Lofberg R, Nordenvall B, Ost A, Hellers G. The risk of colorectal cancer in ulcerative colitis. An epidemiologic study. Scand J Gastroenterol 1987; 22: $1193-9$

14 Ekbom A, Helmick C, Zack M, Adami HO. Ulcerative colitis and colorectal cancer. A population-based study. N Engl J Med 1990; 323: 1228 33

15 Danesh J. Helicobacter pylori and gastric cancer: time for mega-trials? Br J Cancer 1999; 80: 927-9

16 Dixon MF. Helicobacter pylori and peptic ulceration: histopathological aspects. J Gastroenterol Hepatol 1991; 6: 125 - 30

17 Nomura A, Stemmermann GN, Chyou PH, Kato I, Perez-Perez GI, Blaser MJ. Helicobacter pylori infection and gastric carcinoma among Japanese Americans in Hawaii. N Engl J Med 1991; 325: 1132 -6

18 Miehlke S, Kirsch C, Agha-Amiri K, Gunther T, Lehn N, Malfertheiner P et al. The Helicobacter pylori vacA s1, $\mathrm{m} 1$ genotype and cagA is associated with gastric carcinoma in Germany. Int J Cancer 2000; 87: 322 - 7

19 Soll AH. Consensus conference. Medical treatment of peptic ulcer disease. Practice guidelines. Practice parameters committee of the American college of gastroenterology. JAMA 1996; 275: 622 -9

20 Mohar A, Ley C, Guarner J, Herrera-Goepfert R, Figueroa LS, Halperin D et al. Eradication rate of Helicobacter pylori in a Mexican population at high risk for gastric cancer and use of serology to assess cure. Am J Gastroenterol 2002; 97: 2530-5

21 Ley C, Mohar A, Guarner J, Herrera-Goepfert R, Figueroa LS, Halperin D et al. Helicobacter pylori eradication and gastric preneoplastic conditions: a randomized, double-blind, placebo-controlled trial. Cancer Epidemiol Biomarkers Prev 2004; 13: 4-10

22 Davila JA, Morgan RO, Shaib Y, McGlynn KA, El-Serag HB. Hepatitis C infection and the increasing incidence of hepatocellular carcinoma: a population-based study. Gastroenterology 2004; 127: 1372 - 80

23 Omer RE, Kuijsten A, Kadaru AM, Kok FJ, Idris MO, El Khidir IM et al. Population-attributable risk of dietary aflatoxins and hepatitis B virus infection with respect to hepatocellular carcinoma. Nutr Cancer 2004; 48: $15-21$

24 Montalto G, Cervello M, Giannitrapani L, Dantona F, Terranova A, Castagnetta LA. Epidemiology, risk factors, and natural history of hepatocellular carcinoma. Ann N Y Acad Sci 2002; 963: 13-20

25 Fattovich G, Stroffolini T, Zagni I, Donato F. Hepatocellular carcinoma in cirrhosis: incidence and risk factors. Gastroenterology 2004; 127 : S35-50

26 Liang TJ, Heller T. Pathogenesis of hepatitis C-associated hepatocellular carcinoma. Gastroenterology 2004; 127: S62 - 71

27 Butel JS. Viral carcinogenesis: revelation of molecular mechanisms and etiology of human disease. Carcinogenesis 2000; 21: 405-26

28 Chen MG. Progress and problems in schistosomiasis control in China. Trop Med Parasitol 1989; 40: $174-6$

29 Thomas JE, Bassett MT, Sigola LB, Taylor P. Relationship between bladder cancer incidence, Schistosoma haematobium infection, and geographical region in Zimbabwe. Trans R Soc Trop Med Hyg 1990; 84: $551-3$

30 Anjarwalla KA. Carcinoma of the bladder in the coast province of Kenya. East Afr Med J 1971; 48: 502 -9

31 Parkin DM, Srivatanakul P, Khlat M, Chenvidhya D, Chotiwan P, Insiripong $S$ et al. Liver cancer in Thailand. I. A case-control study of cholangiocarcinoma. Int J Cancer 1991; 48: 323 -8

32 Kwak MK, Wakabayashi N, Itoh K, Motohashi H, Yamamoto M, Kensler $T W$. Modulation of gene expression by cancer chemopreventive di- 
thiolethiones through the Keap1-Nrf2 pathway. Identification of novel gene clusters for cell survival. J Biol Chem 2003; 278: 8135-45

33 Khor TO, Huang MT, Prawan A, Liu Y, Hao X, Yu S et al. Increased susceptibility of Nrf2 knockout mice to colitis-associated colorectal cancer. Cancer Prev Res 2008; 1: 187-91.

34 Karin M. NF-kappaB and cancer: mechanisms and targets. Mol Carcinogen 2006; 45: $355-61$

35 Ghosh S, May MJ, Kopp EB. NF-kappa B and Rel proteins: evolutionarily conserved mediators of immune responses. Annu Rev Immunol 1998; 16: $225-60$

36 Amit S, Ben-Neriah Y. NF-kappaB activation in cancer: a challenge for ubiquitination- and proteasome-based therapeutic approach. Semin Cancer Biol 2003; 13: $15-28$

37 Khor TO, Huang MT, Kwon KH, Chan JY, Reddy BS, Kong AN. Nrf2-deficient mice have an increased susceptibility to dextran sulfate sodiuminduced colitis. Cancer Res 2006; 66: 11580-4

38 Cho HY, Reddy SP, Yamamoto M, Kleeberger SR. The transcription factor NRF2 protects against pulmonary fibrosis. Faseb J 2004; 18: 1258 -60

39 Ishii $Y$, Itoh K, Morishima Y, Kimura T, Kiwamoto T, Iizuka T et al. Transcription factor Nrf2 plays a pivotal role in protection against elastase-induced pulmonary inflammation and emphysema. J Immunol 2005; 175: $6968-75$

40 Rangasamy T, Cho CY, Thimmulappa RK, Zhen L, Srisuma SS, Kensler TW et al. Genetic ablation of Nrf2 enhances susceptibility to cigarette smoke-induced emphysema in mice. J Clin Invest 2004; 114: 1248 59

41 Rangasamy T, Guo J, Mitzner WA, Roman J, Singh A, Fryer AD et al. Disruption of Nrf2 enhances susceptibility to severe airway inflammation and asthma in mice. J Exp Med 2005; 202: 47 - 59

42 Thimmulappa RK, Lee H, Rangasamy T, Reddy SP, Yamamoto M, Kensler TW et al. Nrf2 is a critical regulator of the innate immune response and survival during experimental sepsis. J Clin Invest 2006; 116: 984-95

43 Liu GH, Qu J, Shen X. NF-kappaB/p65 antagonizes Nrf2-ARE pathway by depriving CBP from $\mathrm{Nrf} 2$ and facilitating recruitment of HDAC3 to MafK. Biochim Biophys Acta 2008; 1783: 713 - 27

44 Yang H, Magilnick N, Ou X, Lu SC. Tumour necrosis factor alpha induces co-ordinated activation of rat GSH synthetic enzymes via nuclear factor kappaB and activator protein-1. Biochem J 2005; 391: 399-408

45 Bosetti C, Gallus S, La Vecchia C. Aspirin and cancer risk: an updated quantitative review to 2005. Cancer Causes Control 2006; 17: 871 -88

46 Chan JM, Giovannucci EL. Vegetables, fruits, associated micronutrients, and risk of prostate cancer. Epidemiol Rev 2001; 23: 82 -6

47 Chen C, Yu R, Owuor ED, Kong AN. Activation of antioxidant-response element (ARE), mitogen-activated protein kinases (MAPKs) and caspases by major green tea polyphenol components during cell survival and death. Arch Pharm Res 2000; 23: 605-12

48 Campbell JK, Canene-Adams K, Lindshield BL, Boileau TW, Clinton SK, Erdman JW Jr. Tomato phytochemicals and prostate cancer risk. J Nutr 2004; 134: 3486S-92S

49 Chiao JW, Wu H, Ramaswamy G, Conaway CC, Chung FL, Wang L et al. Ingestion of an isothiocyanate metabolite from cruciferous vegetables inhibits growth of human prostate cancer cell xenografts by apoptosis and cell cycle arrest. Carcinogenesis 2004; 25: $1403-8$

50 Miller EC, Giovannucci E, Erdman JW Jr, Bahnson R, Schwartz SJ, Clinton SK. Tomato products, lycopene, and prostate cancer risk. Urol Clin North Am 2002; 29: 83-93

51 Clinton SK, Emenhiser C, Schwartz SJ, Bostwick DG, Williams AW, Moore $B J$ et al. cis-trans-Lycopene isomers, carotenoids, and retinol in the human prostate. Cancer Epidemiol Biomarkers Prev 1996; 5: 823 - 33

52 Giovannucci E, Ascherio A, Rimm EB, Stampfer MJ, Colditz GA, Willett $W C$. Intake of carotenoids and retinol in relation to risk of prostate cancer. J Natl Cancer Inst 1995; 87: 1767 - 76

53 Hecht SS, Chung FL, Richie JP Jr, Akerkar SA, Borukhova A, Skowronski L et al. Effects of watercress consumption on metabolism of a tobaccospecific lung carcinogen in smokers. Cancer Epidemiol Biomarkers Prev 1995; 4: 877-84

54 Cohen JH, Kristal AR, Stanford JL. Fruit and vegetable intakes and prostate cancer risk. J Natl Cancer Inst 2000; 92: 61 -8

55 Kristal AR, Lampe JW. Brassica vegetables and prostate cancer risk: a review of the epidemiological evidence. Nutr Cancer 2002; 42: 1 -9

56 Zhang $Y$, Talalay P. Anticarcinogenic activities of organic isothiocyanates: chemistry and mechanisms. Cancer Res 1994; 54: 1976s-81s

57 Hecht SS. Chemoprevention of cancer by isothiocyanates, modifiers of carcinogen metabolism. J Nutr 1999; 129: 768S-74S
58 Hayes JD, Kelleher MO, Eggleston IM. The cancer chemopreventive actions of phytochemicals derived from glucosinolates. Eur J Nutr 2008; 47 2: $73-88$

59 Heiss E, Herhaus C, Klimo K, Bartsch H, Gerhauser C. Nuclear factor kappa $\mathrm{B}$ is a molecular target for sulforaphane-mediated anti-inflammatory mechanisms. J Biol Chem 2001; 276: $32008-15$

$60 \mathrm{Xu}$ C, Shen G, Chen C, Gelinas C, Kong AN. Suppression of NF-kappaB and NF-kappaB-regulated gene expression by sulforaphane and PEITC through IkappaBalpha, IKK pathway in human prostate cancer PC-3 cells. Oncogene 2005; 24: 4486-95

61 Jeong WS, Kim IW, Hu R, Kong AN. Modulatory properties of various natural chemopreventive agents on the activation of NF-kappaB signaling pathway. Pharm Res 2004; 21: $661-70$

62 Shen G, Khor TO, Hu R, Yu S, Nair S, Ho CT et al. Chemoprevention of familial adenomatous polyposis by natural dietary compounds sulforaphane and dibenzoylmethane alone and in combination in ApcMin/+ mouse. Cancer Res 2007; 67: 9937-44

63 Dey M, Ribnicky D, Kurmukov AG, Raskin I. In vitro and in vivo anti-inflammatory activity of a seed preparation containing phenethylisothiocyanate. J Pharmacol Exp Ther 2006; 317: 326 - 33

64 Ramos-Gomez M, Dolan PM, Itoh K, Yamamoto M, Kensler TW. Interactive effects of nrf2 genotype and oltipraz on benzo[ $a]$ pyrene-DNA adducts and tumor yield in mice. Carcinogenesis 2003; 24: 461 -7

65 Fahey JW, Haristoy X, Dolan PM, Kensler TW, Scholtus I, Stephenson KK et al. Sulforaphane inhibits extracellular, intracellular, and antibioticresistant strains of Helicobacter pylori and prevents benzo[a]pyreneinduced stomach tumors. Proc Natl Acad Sci U S A 2002; 99: 7610 - 5

66 Kensler TW, Chen JG, Egner PA, Fahey JW, Jacobson LP, Stephenson KK et al. Effects of glucosinolate-rich broccoli sprouts on urinary levels of aflatoxin-DNA adducts and phenanthrene tetraols in a randomized clinical trial in He Zuo township, Qidong, People's Republic of China. Cancer Epidemiol Biomarkers Prev 2005; 14: 2605-13

67 Bengmark S. Curcumin, an atoxic antioxidant and natural NFkappaB cyclooxygenase-2, lipooxygenase, and inducible nitric oxide synthase inhibitor: a shield against acute and chronic diseases. JPEN J Parenter Enteral Nutr 2006; 30: 45-51

68 Surh YJ, Chun KS, Cha HH, Han SS, Keum YS, Park KK et al. Molecular mechanisms underlying chemopreventive activities of anti-inflammatory phytochemicals: down-regulation of COX-2 and iNOS through suppression of NF-kappa B activation. Mutat Res 2001; 480-481: $243-68$

69 Conney AH, Lysz T, Ferraro T, Abidi TF, Manchand PS, Laskin JD et al. Inhibitory effect of curcumin and some related dietary compounds on tumor promotion and arachidonic acid metabolism in mouse skin. Adv Enzyme Regul 1991; 31: 385 - 96

70 Huang MT, Ma W, Yen P, Xie JG, Han J, Frenkel K et al. Inhibitory effects of topical application of low doses of curcumin on 12-O-tetradecanoylphorbol 13-acetate-induced tumor promotion and oxidized DNA bases in mouse epidermis. Carcinogenesis 1997; 18: 83-8

71 Kumar A, Dhawan S, Hardegen NJ, Aggarwal BB. Curcumin (diferuloylmethane) inhibition of tumor necrosis factor (TNF)-mediated adhesion of monocytes to endothelial cells by suppression of cell surface expression of adhesion molecules and of nuclear factor-kappaB activation. Biochem Pharmacol 1998; 55: 775-83

72 Plummer SM, Holloway KA, Manson MM, Munks RJ, Kaptein A, Farrow S et al. Inhibition of cyclo-oxygenase 2 expression in colon cells by the chemopreventive agent curcumin involves inhibition of NF-kappaB activation via the NIK/IKK signalling complex. Oncogene 1999; 18: $6013-20$

$73 \mathrm{Kim} \mathrm{JH,} \mathrm{Xu} \mathrm{C,} \mathrm{Keum} \mathrm{YS,} \mathrm{Reddy} \mathrm{B,} \mathrm{Conney} \mathrm{A,} \mathrm{Kong} \mathrm{AN.} \mathrm{Inhibition} \mathrm{of} \mathrm{EGFR}$ signaling in human prostate cancer PC-3 cells by combination treatment with beta-phenylethyl isothiocyanate and curcumin. Carcinogenesis 2006; 27: 475-82

74 Dorai T, Cao YC, Dorai B, Buttyan R, Katz AE. Therapeutic potential of curcumin in human prostate cancer. III. Curcumin inhibits proliferation, induces apoptosis, and inhibits angiogenesis of LNCaP prostate cancer cells in vivo. Prostate 2001; 47: 293-303

75 Rao CV, Simi B, Reddy BS. Inhibition by dietary curcumin of azoxymethane-induced ornithine decarboxylase, tyrosine protein kinase, arachidonic acid metabolism and aberrant crypt foci formation in the rat colon. Carcinogenesis 1993; 14: 2219-25

76 Shen G, Xu C, Hu R, Jain MR, Gopalkrishnan A, Nair S et al. Modulation of nuclear factor E2-related factor 2-mediated gene expression in mice liver and small intestine by cancer chemopreventive agent curcumin. Mol Cancer Ther 2006; 5: 39-51 
77 De Marzo AM, Platz EA, Sutcliffe S, Xu J, Gronberg H, Drake CG et al. Inflammation in prostate carcinogenesis. Nat Rev Cancer 2007; 7: 256-69

78 Coussens LM, Werb Z. Inflammation and cancer. Nature 2002; 420: $860-7$

79 Herrera LA, Benitez-Bribiesca L, Mohar A, Ostrosky-Wegman P. Role of infectious diseases in human carcinogenesis. Environ Mol Mutagen 2005; 45: $284-303$

80 Hold GL, El-Omar ME. Genetic aspects of inflammation and cancer. Biochem J 2008; 410: 225 - 35

81 Osburn WO, Kensler TW. Nrf2 signaling: An adaptive response pathway for protection against environmental toxic insults. Mutat Res 2007; 659: $31-9$

82 Shpitz B, Giladi N, Sagiv E, Lev-Ari S, Liberman E, Kazanov D et al. Celecoxib and curcumin additively inhibit the growth of colorectal cancer in a rat model. Digestion 2006; 74: $140-4$

83 Adhami VM, Malik A, Zaman N, Sarfaraz S, Siddiqui IA, Syed DN et al. Combined inhibitory effects of green tea polyphenols and selective cyclooxygenase-2 inhibitors on the growth of human prostate cancer cells both in vitro and in vivo. Clin Cancer Res 2007; 13: 1611 - 9

84 Riedel SB, Fischer SM, Sanders B, Kline K. Vitamin E analog, alpha-tocopherol ether-linked acetic acid analog, alone and in combination with celecoxib, reduces multiplicity of ultraviolet-induced skin cancers in mice. Anticancer Drugs 2008; 19: 175 - 81

85 Zhang S, Lawson KA, Simmons-Menchaca M, Sun L, Sanders BG, Kline K. Vitamin $E$ analog alpha-TEA and celecoxib alone and together reduce human MDA-MB-435-FL-GFP breast cancer burden and metastasis in nude mice. Breast Cancer Res Treat 2004; 87: 111 - 21

86 Buecher B, Thouminot C, Menanteau J, Bonnet C, Jarry A, Heymann MF et $a l$. Fructooligosaccharide associated with celecoxib reduces the number of aberrant crypt foci in the colon of rats. Reprod Nutr Dev 2003; 43: $347-56$

87 Bobe G, Wang B, Seeram NP, Nair MG, Bourquin LD. Dietary anthocyanin-rich tart cherry extract inhibits intestinal tumorigenesis in APC (Min) mice fed suboptimal levels of sulindac. J Agric Food Chem 2006; 54: $9322-8$

88 Ohishi T, Kishimoto Y, Miura N, Shiota G, Kohri T, Hara Y et al. Synergistic effects of (-)-epigallocatechin gallate with sulindac against colon carcinogenesis of rats treated with azoxymethane. Cancer Lett 2002; 177: $49-56$

89 Suganuma M, Ohkura Y, Okabe S, Fujiki H. Combination cancer chemoprevention with green tea extract and sulindac shown in intestinal tumor formation in Min mice. J Cancer Res Clin Oncol 2001; 127: 69-72 